\title{
CIÊNCIA E EDUCAÇÃO EM PAULO FREIRE: PRESSUPOSTOS EPISTEMOLÓGICOS PARA O ENSINO DE CIÊNCIAS
}

DOI: $10.48075 / R I . V 2412.25602$

Juliano Peroza ${ }^{1}$

RESUMO: Este artigo apresenta uma discussão sobre o ensino de Ciências em Paulo Freire. O objetivo intenciona compreender os pressupostos epistêmicos freirianos a respeito da relação entre saber popular e conhecimento científico, bem como sua concepção de ensino-aprendizagem, para apresentar algumas considerações sobre o ensino de Ciências. Trata-se de uma investigação bibliográfica, com base no referencial metodológico da hermenêutica, cuja finalidade é interpretar e compreender textos no intuito de explicitar os horizontes do seu próprio sentido. Conclui-se que o pensamento político-pedagógico freiriano não sugere, propriamente, métodos ou técnicas para o ensino de Ciências. Por isso contribui de maneira crítica e reflexiva para este campo na medida em que propõe o exercício da dialogicidade e aproximação entre saberes que são apenas diferentes. Ao apontar a proximidade da etnociência com suas concepções de educação, Freire refuta o etnocentrismo acadêmico e provoca os educadores e pesquisadores para que aprofundem sempre mais a compreensão crítica da sua prática educativa e investigativa em posição de respeito, diálogo e aprendizado com a especificidade dos elementos culturais e do contexto sócio-histórico em que se insere a ação pedagógica.

\section{SCIENCE AND EDUCATION ACCORDING TO PAULO FREIRE: EPISTEMOLOGICAL PREMISES FOR THE TEACHING OF SCIENCES}

ABSTRACT: This article presents a discussion regarding the teaching of Sciences according to Paulo Freire. The main goal is to understand the Freirian epistemic premises on the relation between popular and scientific knowledge, as well as his conception on teaching-learning, to present some considerations about the teaching of Sciences. It is a bibliographical investigation, based on the methodological reference of hermeneutics, which aims to interpret and comprehend texts in order to clarify the horizons of its own meaning. The conclusion arises that the Freirian politicalpedagogical way of thinking does not suggest, by itself, methods or techniques for the teaching of Sciences. Therefore, it provides critical and reflexive contributions for this field, as it proposes the exercise of dialoguing and bringing together the areas of knowledge that are simply different. By

\footnotetext{
${ }^{1}$ Graduado em Filosofia pela Universidade São Francisco (USF). Mestre e Doutor em Educação pela PUCPR (Pontifícia Universidade Católica do Paraná). É professor de Filosofia no IFPR (Instituto Federal de Educação, Ciência e Tecnologia do Paraná), Campus Irati: E-mail juliano.peroza@ifpr.edu.br.
} 
pointing out the proximity of ethnoscience to its conceptions of education, Freire refutes academic ethnoscience and generates interest in educators and researchers to continuously go further into the specificity of the cultural elements and the social-historical context in which pedagogical action is inserted.

Key Words: Popular knowledge; Liberating Pedagogy; Teaching of Sciences.

\section{INTRODUÇÃO}

A expressividade do pensamento de Paulo Freire no cenário educacional brasileiro e internacional é incontestável. Seja na área de currículo, políticas públicas, filosofia da educação, educação infantil, educação popular, etc., sua influência vem se consolidando como um referencial cada vez mais presente e oportuno para pesquisadores e pesquisadoras que procuram refletir sobre os mais diversos temas com o auxílio dos apontamentos freirianos em suas relações com a educação.

Em estudo realizado por Zauith e Hayashi (2013), procurou-se demonstrar, por meio de uma análise bibliométrica, a influência de Paulo Freire no Ensino de Ciências e na Educação, Ciência, Tecnologia e Sociedade (CTS). Tendo como base de coleta o banco de dados da Capes, as autoras identificaram as tendências e justificativas para a utilização da abordagem freiriana nesta área. Ao todo, encontraram 43 teses e dissertações sobre o Ensino de Ciências, Tecnologia e Sociedade (CTS) e 22 disciplinas ofertadas nestas áreas de conhecimento entre algumas das mais renomadas universidades brasileiras - USP (Universide de São Paulo), UNB (Universidade de Brasília) e UFSC (Universidade Federal de Santa Catarina) - com influências de referencial teórico freiriano. Isto demonstra o quanto o pensamento político-pedagógico de Paulo Freire também tem se constituído como um possível interlocutor para a área do Ensino de Ciências, embora ele nunca tenha sistematizado algo sobre a temática.

Quando destacamos esta "assistematicidade", não significa que o autor a tenha renegado sua devida importância, pelo contrário, Freire sempre se demonstrou profundamente interessado pelos vários aspectos que envolvem a totalidade da prática educativa. Por isso devemos perceber nas entrelinhas do seu discurso a recorrência sobre o assunto, de modo a demonstrar que o tema em questão está implícito no desenvolvimento dialético do seu pensamento político-pedagógico. 
De modo geral, o que pretendemos discutir neste artigo, que tem caráter de ensaio, são os pressupostos a respeito do saber popular e o saber científico, as relações entre ensino e aprendizagem e, como consequência, destacar alguns os apontamentos políticopedagógicos para o ensino de Ciências na perspectiva freiriana. Assumimos, como ponto de partida, que o pensamento de Paulo Freire não estabelece um receituário de métodos nem técnicas específicas a serem utilizadas em qualquer prática de ensino, pelo contrário, compreendemos que o educador sugere, por meio de inúmeros apontamentos, várias provocações e considerações reflexivas sobre os pressupostos epistemológicos e políticopedagógicos que subjazem à prática educativa problematizadora, os quais, porventura, podem servir de fundamento para este componente curricular.

Para atingir este objetivo tomaremos como referencial metodológico a hermenêutica, a qual pode ser considerada uma "teoria das operações da compreensão em sua relação com a interpretação dos textos" (Ricoeur,1988). A hermenêutica é uma modalidade da teoria do conhecimento (epistemologia) que não se preocupa apenas com o fenômeno, mas com a ação de compreendê-lo, pois defende que o sentido da obra está ligado a sua organização interna, isto é, ao próprio texto. Deste modo, a interpretação se faz também uma "explicitação", um exercício para trazer à tona elementos que aparentemente estariam "imperceptíveis" por se encontrarem "difusos", ou "embaralhados" em meio à trama complexa de conceitos que se irmanam na totalidade de uma obra. Assim, nossa tarefa hermenêutica propõe uma aproximação às noções freirianas de conhecimentos científicos e saberes populares, "ensino-aprendizagem", práxis, dialogicidade, cultura, "suleamento" e etnociência para explicitar os pressupostos da sua concepção de "ensino de Ciências".

Em geral, Paulo Freire lança um duplo desafio aos educadores desta área de conhecimento: primeiro, para que se inspirem na metodologia utilizada pelos etnocientistas, a fim de que possam dialogar com as diferentes realidades culturais e aprendam a reconhecer a "episteme" implícita na curiosidade do senso comum e do saber popular. E, segundo, para que aprofundem o exercício contínuo e crítico de contextualização conjuntural e sócio-histórica do conhecimento sobre os conteúdos abordados na área de ciências em relação dialética com as dimensões econômicas, culturais, políticas e éticas.

Esta reflexão visa contribuir para o debate sobre a problematização políticopedagógica de Paulo Freire para o ensino de Ciências, uma vez que o autor vem adquirindo cada vez mais relevância neste campo educacional. Explicitar alguns dos pressupostos 
elementares para esta discussão é o que pretendemos nestas páginas, a fim de estimular a investigação para além de certas tendências reducionistas.

\section{A RELAÇÃO ENTRE SABER POPULAR E O CONHECIMENTO CIENTÍFICO EM PAULO FREIRE}

O educador pernambucano, Paulo Freire (1922-1997), se tornou mundialmente conhecido pelo seu método de alfabetização. Entre as décadas de 1950 e 1960 desenvolveu experiências de alfabetização voltadas para jovens e adultos no nordeste brasileiro com o objetivo de que estes aprendessem a ler e escrever a partir do contexto existencial em que se encontravam, a fim de que a "leitura do mundo" - saber de experiência feito, como Freire chamava - servisse de base para o aprendizado da "leitura da palavra". Ou seja, o ato de aprender a ler e escrever estava também associado ao desenvolvimento de visão crítica da realidade, à compreensão das condições políticas e econômicas da região, de modo que o educando superasse uma determinada compreensão ingênua da realidade, se conscientizasse a respeito dos problemas do seu contexto, e se engajasse em sua transformação.

Para que isso fosse possível, Freire propôs algumas mudanças na organização do espaço e do tempo educativo para propiciar um ambiente favorável à realidade dos educandos, geralmente camponeses e de classes populares. As "classes" foram substituídas pelos "círculos de cultura", os "alunos" pelos "participantes dos grupos de discussões", os "professores" passaram a ser compreendidos como "coordenadores de debates". Igualmente, a "aula" era substituída pelo "diálogo" entre educador e educandos e o "programa" (currículo) por "situações existenciais" (BEISIEGEL, 2010, p. 42).

Em sua obra Pedagogia do Oprimido (1988), Freire elaborou uma dura crítica àquilo que ele denominou de "Educação Bancária", uma educação em que o educador "deposita" informações e conhecimentos na mente dos educandos sem considerar as especificidades concretas do seu contexto. Esse modelo de educação seria uma forma de domesticar os educandos, de acomodá-los à simples memorização de informações para manterem-se passivos, inertes e ingênuos frente aos problemas que afligiam sua existência. Por isso, seria uma educação "antidialógica", por negar o diálogo e manter a opressão, caracterizando-se pela conquista, a divisão, a manipulação e a invasão cultural. Para superar este modelo bancário de educação, Freire elaborou aquilo que chamou de "Educação Problematizadora", 
que se nutre das palavras e dos temas "geradores" extraídos do contexto em que se encontram as pessoas. Esta concepção de educação tem um caráter libertador, pois se embasa no diálogo crítico sobre a existência e a vida, uma "ação dialógica" que se caracteriza pela colaboração, a união, a organização e a síntese cultural.

Obviamente que, para esta concepção bancária de educação, o educador é aquele que sabe, enquanto o educando é quem ignora completamente, ou é "vazio de conhecimentos". Nesta concepção ocorre uma separação entre teoria e prática, onde a teoria é vista hierarquicamente como superior à prática. O saber teórico, erudito, também denominado de conhecimento científico, sistematizado e formalmente organizado, seria uma característica atribuída aos sábios, detentores de uma linguagem que codifica a verdade e que deve iluminar a ignorância das classes populares, cujos conhecimentos são tachados de ingênuos (FISCHER; LOUSADA, 2008).

Já para a educação problematizadora, o educando é uma fonte inesgotável de conhecimentos ou o que Freire (2006b) chama de "saberes de experiência feito", síntese da relação espontânea da subjetividade do indivíduo com o mundo que o cerca, frente aos elementos da sua cultura. O "saber de experiência feito" é o acúmulo de todas as experiências que permitiram aos indivíduos elaborar uma certa visão de mundo para compreender e explicar a realidade que os cerca.

Portanto, tanto o senso comum, quanto o saber popular, não podem ser ignorados pelo educador problematizador, pois estes, por meio da ação dialógica, representam os elementos basilares da compreensão de mundo das classes populares e revelam, à sua maneira, o arcabouço cultural que unifica a sua compreensão de mundo. 0 educador problematizador se torna um intérprete dos conhecimentos vinculados ao cotidiano dos indivíduos, nos quais se encontram saberes configurados historicamente e fazem parte dos seus códigos culturais. Neste sentido, ninguém é absolutamente sábio, muito menos, absolutamente ignorante:

Ninguém ignora tudo. Ninguém tudo sabe. A absolutização da ignorância, ademais de ser a manifestação de uma consciência ingênua da ignorância e do saber, é instrumento de que se serve a consciência dominadora para a manipulação dos chamados "incultos". Dos "absolutamente ignorantes" que, "incapazes de dirigir-se", necessitam da "orientação", da "direção", da "condução" dos que se consideram a si mesmos "cultos e superiores" (FREIRE, 1967, p. 104-105) 
De acordo com Freire, a absolutização da ignorância é uma estratégia para camuflar as relações de dominação, de modo que as classes dominadas sintam a necessidade de que "alguém" Ihes explique o mundo, a realidade pois, alienados, não "sabem que sabem", ou melhor, desqualificam seu saber como "ilegítimo" em detrimento do saber acadêmico, referendado e validado por seres humanos supostamente "iluminados". Isso se dá porque ocorreu, historicamente, um processo de elitização do saber erudito e, ao mesmo tempo, de pauperização do saber das classes populares.

A linguagem das classes populares se refere à concretude da vida, enquanto a linguagem erudita se refere ao conceito. Se o erudito estiver demasiado distante da realidade das classes populares, afasta-se de tal modo do concreto que o seu conceito se esvazia, se imobiliza e fica estático, "convertendo-se em pura descrição" (FREIRE; FAUNDEZ, 1985, p. 33-34). Daí que, para Freire, é preciso haver sempre mais uma aproximação entre o conhecimento científico e o saber popular, pois entre ambos deve haver uma solidariedade que harmonize "realidade-conceito-realidade".

Ocorre que, o conhecimento científico, ao se supervalorizar na teoria, cria um certo abismo em relação ao saber popular que está vinculado à prática cotidiana. A consequência desta atitude gera uma incomunicabilidade com o mundo da vida, afastando a ciência do mundo concreto e enclausurando-a numa redoma academicista. A escola, muitas vezes, se elitiza e considera a preponderância dos conhecimentos científicos como se fossem respostas acabadas para perguntas que não foram feitas naquele determinado contexto:

A escola é autoritária e elitista porque avaliza um saber inteiramente pronto, um saber pretensamente acabado. Essa concepção do conhecimento é um erro científico, uma antiverdade epistemológica. Não existe um saber fechado. Todo conhecimento surge na história, jamais fora dela. Todo novo saber nasce do envelhecimento de um saber anterior que também foi inovador em seu tempo. Nasce, precisamente, quando se aceita - com humildade - que esse saber também envelhece. Alguns cientistas parecem esquecer-se disso de vez em quando... Com essa afirmação, nem eu nem você pretendemos, sequer por um instante, paralisar, encerrar os alunos no que sabiam antes de irem à escola. Para nós, deve ser justamente o contrário. Desejamos que aprendam a saber melhor o que já sabiam antes, para que se transformem, por sua vez, nos criadores de um saber que ainda está por surgir (FREIRE, 1991, p. 3-4).

A educação que se funda na ação dialógica não admite ruptura entre senso comum e o saber acadêmico, pois ruptura implica em considerar esferas distintas, impossíveis de se comunicarem. Para superar este distanciamento se requer um espírito de abertura, que 
exige humildade e despojamento para ir ao encontro do diferente, mas também permitir-lhe o acesso àquilo que, à primeira vista, lhe parece estranho. Todavia, deve-se tomar muito cuidado para não supervalorizar o saber popular que desconsidera os achados provenientes das pesquisas e descobertas realizadas na investigação acadêmica, o que pode incorrer num espontaneísmo, praticismo, ou pragmatismo utilitarista, pois ignora a necessidade de elaborar uma reflexão rigorosa sobre os limites e as possibilidades do conhecimento para além de certas experiências práticas. ${ }^{2}$

Para superar sectarismos entre o saber popular e o conhecimento científico, entre a teoria e a prática, Freire sugere que a pedagogia problematizadora exercite a práxis, de modo que a ação (prática) seja inseparável da reflexão (sua teorização) a fim de que haja uma constante superação e ambas (teoria e prática), para que criem um elo significativo e se retroalimentem continuamente. A práxis (ação + reflexão) é a unidade inseparável entre teoria e prática, sem sobreposição, dicotomia ou classificação hierárquica de um tipo de conhecimento sobre o outro, mas de recíproca comunicação, troca de significados e complementariedade crítica.

A perspectiva da práxis permite, tanto ao cientista, quanto ao educador, desenvolverem certa aptidão para reconhecer as limitações e condicionamentos culturais que incidem sobre os conhecimentos de um determinado grupo social para inteligir seus códigos, apreender sua lógica de funcionamento e captar seus significados. O processo histórico de um grupo social também é sinônimo do seu próprio desenvolvimento cultural e intelectual, portanto, responde às exigências existenciais da sua época em sua localidade. Para exemplificar esta consideração, Freire (2004) traz a análise sobre o caso de um conhecimento prático numa comunidade indígena relativo à pesca:

[...] o índio não optou por pescar flechando. O seu estágio cultural e econômico, social, etc. é esse, o que não significa que ele não saiba, que não possa saber de coisas que se dera fora desse espaço cultural. Então eu acho que o meu respeito pela identidade cultural do outro exige de mim que eu não pretenda impor ao outro uma forma de ser da minha cultura, que tem outros cursos, mas também o meu respeito não me impõe negar

\footnotetext{
${ }^{2}$ Sobre esta relação comenta Freire: “Tem havido maneiras diferentes de compreensão negativa e, portanto, de crítica, a esta defesa do saber popular, em que faz tanto me empenho. Negação do saber popular tão contestável quanto sua mitificação, quanto sua exaltação, de natureza "basista". Basismo e elitismo, de tal maneira sectários que presos à e em sua verdade se tornam incapazes de ir mais além de si mesmos. (CF. FREIRE, Paulo. Pedagogia da Esperança: um reencontro com a Pedagogia do Oprimido. São Paulo: Paz e Terra, 2006a, p. 85).
} 
ao outro o que a curiosidade do outro e o que ele quer saber mais daquilo que a cultura dele propõe (FREIRE, 2004, p. 83).

Percebe-se que as considerações de Freire frente a relação entre saber científico (cultura erudita) e o saber popular (aqui representado pelo conhecimento sobre a pesca com arco e flecha) não é de ordem meramente epistêmica, mas também está impregnada de um caráter ético, que se funda no respeito e na tolerância pelas especificidades do universo cultural que circunscreve um saber diferente da cultura em que determinados grupos sociais se encontram. Quando se desconsidera esta peculiaridade, numa posição de horizontalidade frente às diferenças cognitivas que representam o mundo, incorre-se no equívoco de sobredeterminar verticalmente o saber científico às demais formas de conhecimento.

Isso implica em reconhecer, primeiramente, que o saber popular responde a um determinado estágio cultural e econômico. Seus limites estão circunscritos por condições históricas que delimitam os horizontes das capacidades cognitivas e as potencialidades críticas dos indivíduos que se encontram nesta realidade. Esses saberes jamais podem ser julgados meramente como supérfluos, ou inválidos, só por que não passaram pelo crivo do rigor acadêmico. O saber popular tem sua chancela na prática, atende às necessidades específicas do grupo a que pertence e, além disso, é legitimado, mantido e transmitido pela tradição.

Freire entende que, se há uma hierarquização do saber "científico" (superação) em relação ao saber "popular", isto se dá por causa de uma relação de poder: "e, precisamente porque o nosso lado é o lado do poder, a superação se dá em favor de nós. Se o lado do poder estivesse no lado dos índios, a superação seria deles" (FREIRE, 2004, p. 88). Mitigar estas relações de poder é uma condição sine qua non para uma aproximação entre diferentes formas de saberes, para se admitir que ninguém possui, definitivamente, a verdade. E um modo de fazer isso consiste no reconhecimento recíproco de que apenas possuímos saberes diferentes:

É por isso que, nessa questão epistemológica da passagem do senso comum para um saber científico, eu acho que há uma superação, e não uma ruptura. Quer dizer, a curiosidade do índio que diz pro matemático: "não, não, é um equívoco, é uma ilusão dos seus olhos" ${ }^{3}$, a curiosidade dele

\footnotetext{
${ }^{3}$ Aqui Freire refere-se ao índio explicando ao matemático que para acertar a flecha no peixe não deve apontar para onde seus olhos veem, pois, a imagem do peixe submerso não corresponde ao seu exato estado, é uma "ilusão". O índio sabe disso sem necessariamente explicar a lei da refração (Cf. FREIRE, Paulo. Pedagogia da Tolerância. São Paulo: UNESP Editora, 2004, p. 83).
} 
é igualzinha a curiosidade do Einstein. A diferença é que, antes, Einstein rigorizou os caminhos de aproximação da objetividade, quer dizer, ele tinha nos meios científicos a metodização rigorosa que resulta em achados mais ou menos exatos, mas a curiosidade que motiva, que conduz e empurra o conhecimento é a mesma, a do índio, a minha e a tua (FREIRE, 2004, p. 85).

Portanto, a práxis enquanto indissociabilidade entre teoria e prática também é uma forma de exercício de aproximação entre o saber científico e o saber popular para “compreender como a compreensão do outro se dá" (2004, p. 84), de interpretar o percurso que a curiosidade do outro trilhou para chegar aos seus resultados ou, numa linguagem mais acadêmica, explicitar o "método" utilizado para atingir certos objetivos que responderam aos problemas da sua existência.

A grande questão, para Freire está em reconhecer que a curiosidade que orienta o saber popular e o saber científico é a mesma. O que os diferenciam são os caminhos tomados para orientar esta curiosidade, os quais são determinados pelo estágio cultural e econômico de onde se encontram estas curiosidades. O senso comum, ou o saber popular, contém uma curiosidade ingênua, ou desarmada. O saber científico contém a curiosidade que se "rigorizou" metodicamente em sua aproximação ao objeto. De uma para a outra muda a qualidade, mas não a essência (FREIRE, 2006b, p. 31). Por isso, para Freire, entre o saber popular e o saber científico não há uma ruptura, mas apenas uma superação.

A tarefa, tanto do educador quanto do cientista que se orienta pela ação dialógica da pedagogia problematizadora, consiste em captar aquilo que há de universal no saber popular e no conhecimento científico para aproximá-los, confrontá-los e solidarizá-los a fim de diminuir a distância entre teoria e prática, o abstrato do concreto.

\section{ASPECTOS DA CONCEPÇÃO FREIRIANA DE ENSINO-APRENDIZAGEM}

A categoria "ensino" em Paulo Freire não é utilizada com expressividade em nenhuma de suas obras clássicas originárias, como por exemplo, Educação como prática da liberdade (1967) e Pedagogia do Oprimido (1988). O mesmo acontece com as expressões "ciência", ou "saber científico". Isso acontece, possivelmente, pelo fato de que Freire compreendesse, na época, que os conceitos de "ação" ou "prática" educativa já contivessem, implicitamente, a conotação do ato de ensinar, bem como, o conceito de saber, ou de conhecimento, ou porque também denotassem uma relação imbricada com a ciência, ou o conhecimento científico. 
É somente a partir da década de 1990 que Freire começa a explicitar estas categorias (ensino e ciências) junto à ênfase que dá ao abordar novos temas, como por exemplo: formação de professores, esperança, educação progressista, pós-modernidade, ética, estética, tolerância, mídia (FREIRE, 1992, 2001, 2004, 2006) etc.

Sobre o "ato de ensinar", que está indissociável do "ato de aprender", para Paulo Freire, percebe-se um destaque especial em duas de suas obras: Professora sim, tia nãoCartas a quem ousa ensinar (1997), obra em que dedica a primeira carta para refletir sobre o ato de ensinar; e Pedagogia da Autonomia - Saberes necessários à prática educativa (2006b), a qual versa sobre as virtudes indispensáveis à prática educativa e apresenta 27 (vinte e sete) subcapítulos inicialmente intitulados "Ensinar exige...", o que demonstra sua insistência a respeito de uma série de exigências indispensáveis ao ato de ensinar. Nesta última obra referida, Freire afirma logo na introdução:

Quem ensina, aprende ao ensinar, e quem aprende, ensina ao aprender. Quem ensina, ensina alguma coisa a alguém. Por isso é que, do ponto de vista gramatical, o verbo ensinar é um verbo transitivo-relativo. Verbo que pede um objeto direto - alguma coisa - e um objeto indireto - a alguém. Do ponto de vista democrático em que me situo [...] ensinar é algo mais do que um verbo transitivo-relativo. Ensinar não existe sem aprender e viceversa [...]. Quando vivemos a autenticidade exigida pela prática de ensinaraprender participamos de uma experiência total, diretiva, política, ideológica, gnosiológica, pedagógica, estética e ética, em que a boniteza deve estar de mãos dadas com a decência e com a seriedade (FREIRE, 2006b, p. 23-24).

À primeira vista, numa análise meramente gramatical, a interpretação do verbo ensinar pressupõe que alguém ensine algo a outrem, ou seja, que transfira o que the pertence para um outro que se torna um receptor, além de vazio, também passivo. Esta não seria somente a interpretação gramatical do ato de ensinar, mas também a forma tradicional que definiu a concepção de ensinar historicamente. No entanto, Freire esclarece que sua concepção de ensino está vinculada ao seu ponto de vista democrático, o qual pressupõe diálogo, interação, conflito e troca de sentidos. Por isso, o ato de ensinar não pode estar separado do ato de aprender, pois ambos se dão simultaneamente: aquele que ensina, também aprende, de um lado, porque reconhece um "conhecimento antes aprendido e, de outro, porque, observando a maneira como a curiosidade do aluno aprendiz trabalha para apreender o ensinando-se, sem o que não o aprende, o ensinante se ajuda a descobrir incertezas, acertos, equívocos" (FREIRE, 1997, p. 19). 
Compreendido desta forma, o ato de ensinar não pode ser reduzido a um método ou um conjunto de técnicas com pretensa neutralidade gnosiológica "de transferência de conhecimento da ensinante ao aprendiz. Transferência mecânica de que resulte a memorização maquinal que já critiquei" (FREIRE, 1997, p. 23). Essa "experiência total", referida por Freire, denota a complexidade de uma relação antropológica que não pode ser reduzida a um simples ato mecânico, autômato e estritamente racional em torno de conhecimentos "esterilizados", "depurados" de questões ideológicas, éticas, estéticas, políticas ou afetivas. A tarefa de ensinar também evolve sentimentos, emoções, que se expressam por meio de palavras, gestos e até silêncios, pois tudo é passível de interpretação do ensinante que se torna aprendiz da sua própria prática de ensinar. Sobre esta reflexão, continua Freire:

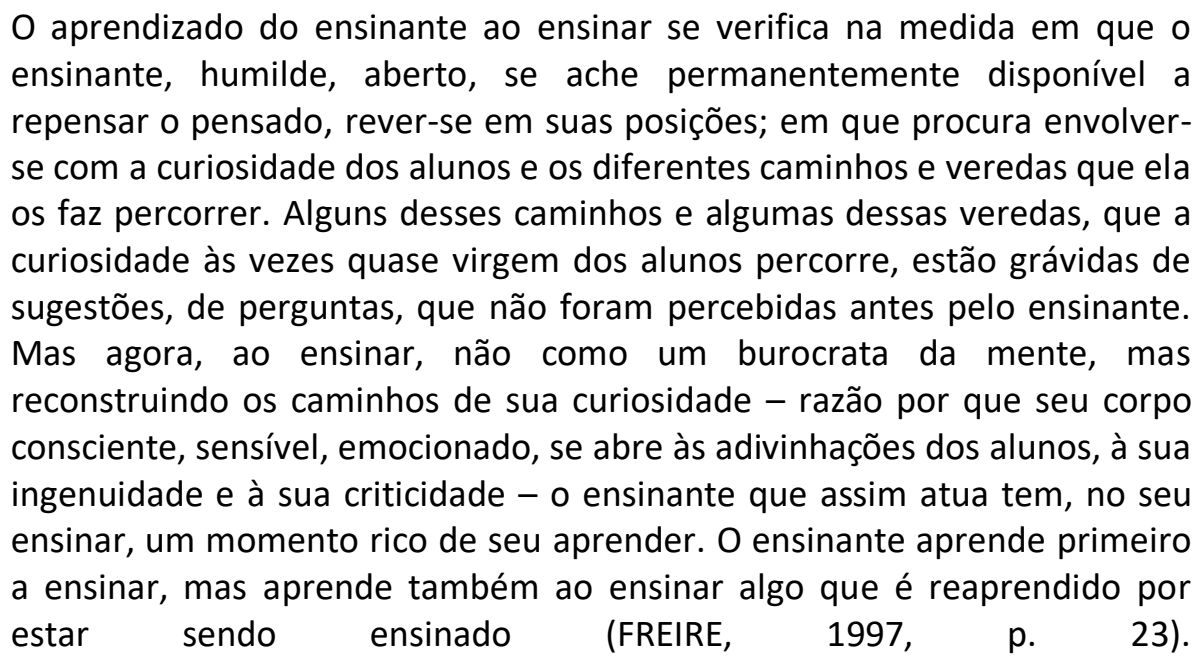

Como foi exposto no início deste artigo sobre a relação entre saber popular e conhecimento científico, a perspectiva freiriana de educação não admite que alguém seja absolutamente ignorante, muito menos onisciente. Todo saber é relativo, porque histórico. Esta condição é indispensável também para o ato de ensinar, pois todo aquele que ensina tem algo a aprender se estiver numa posição de horizontalidade ética em relação àquele que aprende. Portanto, a humildade é indispensável ao ato de "ensinar-aprender", pois é um quesito que permite o desenvolvimento da sensibilidade para perceber detalhes que a arrogância pode obstruir. Sobre isso o autor já afirmava: "eu acho que há muita arrogância nossa, dos intelectuais, dos cientistas (FREIRE, 2004, p. 85). O olhar arrogante pode burocratizar o raciocínio e criar obstáculos aos caminhos da curiosidade, pois provoca o medo e intimida quem está na condição de aprendizado a se expor com liberdade e 
espontaneidade, em seus termos: "queremos uma pedagogia que, sem renunciar às exigências do rigor, admita a espontaneidade, o sentimento, a emoção, e aceite, como ponto de partida, o que eu chamaria de "o aqui e o agora" perceptivo histórico e social dos alunos" (FREIRE, 1991, p. 7).

Etimologicamente, a palavra ensinar, do latim in + signare (marcar com um sinal), quer dizer: conferir significado, dar sentido àquilo que se aprende, "ficar marcado". O educador, ao ensinar, deixa suas marcas (éticas, políticas, afetivas, gnosiológicas, estéticas, etc) no educando, pois impregna de sentido a relação com este em torno do objeto a ser conhecido. Mas o educando, ao aprender também marca (ensina) o educador, caso esteja aberto para perceber os detalhes das perguntas que brotam espontaneamente nos educandos, tímidas, cheias de adivinhações, ou até mesmo ingênuas, ávidas pela busca do inusitado. Por isso, para Freire, o ensino não pode ser tomado como apenas uma dimensão isolada da totalidade que circunscreve a prática educativa:

Toda prática educativa demanda a existência de sujeitos, um que, ensinando, aprende, outro que, aprendendo, ensina, daí o seu cunho gnosiológico; a existência de objetos, conteúdos a serem ensinados e aprendidos; envolve o uso de métodos, de técnicas, de materiais; implica, em função de seu caráter diretivo, objetivo, sonhos, utopias, ideais. Daí a sua politicidade, qualidade que tem a prática educativa de ser política, de não poder ser neutra. Especificamente humana a educação é gnosiológica, é diretiva, por isso política, é artística e moral, serve-se de meios, de técnicas, envolve frustrações, medos, desejos. Exige de mim, como professor, uma competência geral, um saber de sua natureza e saberes especiais, ligados à minha atividade docente (FREIRE, 2006b, p. 69-70).

O educador, ao ensinar, precisa ter consciência de que este ato compreende uma pluralidade de dimensões que vão muito além da transmissão do conteúdo e da utilização de técnicas e métodos. A prática educativa, cujo ato de ensinar é um dos elementos centrais, também necessita desta "competência geral", uma visão global da realidade e das múltiplas conexões possíveis para tecer a sua complexidade: economia, política, antropologia, história, sociologia, arte, tecnologias, conhecimentos científicos e cultura em geral, anatomia, esportes, etc., além dos saberes específicos que correspondem à disciplina em que atua. Esta visão crítica e totalizante da realidade, permite ao educador que, ao mesmo tempo em que ensina os conteúdos, também desafia os educandos para aprenderem a "razão de ser" destes conteúdos, com o intuito de se apropriarem criticamente do conhecimento existente e superem-no, criem o conhecimento novo. O que importa, para Freire, é que se 
desencadeie o desenvolvimento da autonomia cognoscente do educando, para que este seja tutor de sua própria curiosidade, superando suas possíveis ingenuidades com rigorosidade e criticidade.

Insistentemente, somente em sua obra Pedagogia da Autonomia (2006b, pp. 27, 33, $34,37,56,94,95,103)$ Freire alerta para o fato de que o ensino dos conteúdos jamais esteja separado do "pensar certo", que implica em ser rigoroso, problematizador e profundo nas análises sobre os fatos, e da formação ética dos educandos. Uma ética cujo centro é o desenvolvimento das potencialidades do ser humano, crítica contumaz da ética autorreferencial do mercado. Obviamente que, se a prática educativa é uma totalidade de elementos que se complementam, todo exclusivismo do ensino dos conteúdos em relação às circunstâncias políticas, econômicas e históricas da sociedade não passa de um reducionismo gnosiológico, que induz a um "pensar errado", pois fragmenta a realidade em parcelas e inscreve a abordagem dos conteúdos num ostracismo.

Enfim, a pedagogia crítica, problematizadora, não se reduz à estreiteza do tecnicismo cientificista, sinônimo de treinamento e domesticação enviesada de uma suposta neutralidade burocratizante das mentes. Na perspectiva freiriana o ensino, que é inseparável da aprendizagem, precisa ter como ponto de partida o contexto que configura as situaçõeslimite dos educandos, seus problemas e temas mais significativos. Somente a partir desta interação com a realidade é que os conteúdos podem ser sistematizados coletivamente para serem devolvidos de maneira programática, processual e crítica. O educador deve conjugar seriedade e competência para interpretar a linguagem dos educandos, na qual está codificado seu saber acumulado - saber de experiência feito -, a fim de aprender com os desafios da realidade em que está inserido, na medida em que desafia a si mesmo e aos seus educandos a aprenderem aquilo que já sabem, porque superaram a ingenuidade da sua curiosidade para torná-la epistemologicamente crítica.

PRESSUPOSTOS POLÍTICO-PEDAGÓGICOS E EPISTÊMICOS SOBRE O ENSINO DE CIÊNCIAS EM PAULO FREIRE

Feitas as considerações sobre as relações entre saberes populares e conhecimentos científicos, bem como sobre a compreensão de ensino-aprendizagem no pensamento de Paulo Freire, conclui-se que o pensamento político-pedagógico freiriano não aponta métodos, técnicas ou "receituários" para serem utilizados ou transplantados a outras 
realidades em que se dão outras práticas educativas. O que Freire nos oferece é uma reflexão sobre os pressupostos epistemológicos do ato de conhecer-ensinar-aprender a partir de uma visão ampliada da realidade e dos fatos, a qual só pode ser apreendida, intuída e problematizada se forem consideradas as múltiplas determinações que compõem sua concretude. Isso se insere numa perspectiva que Freire chama de "inter" ou "trans" disciplinar da realidade:

O real é, enquanto real, uma totalidade transdisciplinar. E só é apreendido em retotalizações. A inter-(ou trans) disciplinaridade é demanda da natureza e da realidade do mundo. É como se ela dissesse: "vocês, Humanos, podem conhecer-me mas, eu vou logo dizendo que só me conhecerão com a condição de correlacionarem dialogicamente as múltiplas partes ou tendências que são necessárias a vocês (FREIRE, 1994, p. 20).

Com esta afirmação, Freire se aproxima dos pressupostos epistemológicos do Materialismo Histórico e Dialético, o qual afirma que o "concreto é concreto por ser síntese de múltiplas determinações, logo, unidade na diversidade. É por isso que ele é para o pensamento um processo de síntese, um resultado, e não um ponto de partida" (MARX, 1977, p. 218-219). Freire admite que a apreensão da realidade, a qual pressupõe a busca da totalidade é um exercício interdisciplinar contínuo. As "retotalizações", a que se refere, implicam em reconhecer que a realidade é dinâmica, mutável. Portanto, toda visão de conjunto que busque abarcar a totalidade da realidade precisa ser revisada e reanalisada por meio de sínteses. Isto implica numa visão da realidade como um processo, na qual tanto a cultura, a história, quanto a natureza e o ser humano são mutáveis, e passam por transformações:

Por isso é que, para mim, um dos conteúdos essenciais de qualquer programa educativo, de sintaxe, de biologia, de física, de matemática, de ciências sociais é o que possibilita a discussão da natureza mutável da realidade natural como da histórica e vê homens e mulheres como seres não apenas capazes de se adaptar ao mundo mas sobretudo de mudá-lo. Seres curiosos, atuantes, falantes, criadores (FREIRE, 2000, p. 96).

Para Freire, o ensino de Ciências torna-se um local privilegiado para a práxis educativa conscientizadora. Por meio deste componente curricular é possível identificar com precisão como os seres humanos exploram a mutabilidade da natureza, intervém no seu curso e estabelecem conexões entre os elementos naturais do mundo físico que é suporte para a vida humana. A pergunta de Freire seria a seguinte: se o ser humano muda o curso do 
mundo que não fez, por que não seria capaz de mudar o mundo que ele criou, o mundo da cultura, da história, da economia, da política e da ética? Freire vê no ensino de Ciências uma oportunidade privilegiada para desmistificar as falácias dos condicionamentos da ideologia neoliberal, do reacionarismo e do conservadorismo, os quais propagam o imobilismo e o fatalismo político, como se a realidade sócio-histórica fosse imutável.

Assim, compreende-se que Freire intenciona provocar reflexões sobre os pressupostos epistemológicos e político-pedagógicos que subjazem à prática educativa problematizadora do ensino de Ciências. Desafia os educadores deste componente curricular para que se exercitem num duplo sentido: primeiro, no cultivo da sensibilidade para dialogar com as diferentes realidades culturais e socioeconômicas para reconhecer o valor e o significado da curiosidade espontânea do senso comum que está na base da sabedoria popular. $E$, em segundo lugar, para que aprofundem o exercício contínuo e crítico de contextualização conjuntural e histórica dos conhecimentos sobre os conteúdos abordados nas diversas áreas científicas, em perspectiva crítica com relação às dimensões econômicas, culturais, sociais, políticas e éticas: "a competência do conteúdo tem que estar iluminada pela competência política, que esclarece politicamente a razão de ser do conteúdo [...]. Eu não posso ficar apenas no nível do conteúdo, por que devo ultrapassá-lo" (FREIRE, 2018, p. 80-81).

No que se refere à sensibilidade no trato com outras formas de saberes para dialogar com as diferentes realidades socioeconômicas e culturais é preciso, ao ensinar, também aprender a reconhecer a "episteme" implícita no desenvolvimento da curiosidade da sabedoria popular. Sobre isso, Freire refere aos estudos do físico e antropólogo Marcio D’Olne Campos ${ }^{4}$, em suas pesquisas sobre etnociência:

Este vem sendo, hoje, entre nós, no Brasil, um que fazer caro à etnociência. Saber como os grupos populares rurais, indígenas ou não, sabem. Como vêm organizando o seu saber, ou sua ciência agronômica, por exemplo, ou a sua medicina, para o que desenvolveram uma taxionomia amplamente sistematizada das plantas, das ervas, dos matos, dos cheiros, das raízes. E é interessante observar como matizam a exatidão taxionômica com promessas milagreiras. Raízes cujo chá cura, ao mesmo tempo, câncer e

\footnotetext{
${ }^{4}$ Físico e professor da UNICAMP, Marcio D'Olne Campos, traz uma definição sobre etnociência: "Etnociência vem sendo entendida e exercida pela equipe de pesquisadores da Unicamp [...] com diferenças adjetivas não substantivas entre eles, da qual Márcio Campos faz parte, justamente por aqueles que a vêm fazendo como uma etnografia do saber e da tecnologia (etnotecnologia) de contextos culturais diferenciados. Ela é a etnociência feita a partir da academia sobre a outra ciência, da outra cultura. Com ela têm sido estruturados, por exemplo, diversos grupos indígenas do território brasileiro, assim como os caiçaras do Estado de São Paulo [...] como um corpo de conhecimento que articula a ciência e a tecnologia desses povos com a cultura que thes é própria [...]" (Cf. FREIRE, Ana Maria. Notas. In: Pedagogia da Esperança: um reencontro com a Pedagogia do Oprimido. São Paulo: Paz e Terra, 2006a).
} 
dores de amor desfeito; ervas que combatem a impotência masculina. Folhas especiais para o resguardo da parturiente, para a "espinhela caída" etc. (FREIRE, 2006a, p. 135).

De extrema importância para o ensino de Ciências é tentar compreender, epistemologicamente, o percurso que conduziu a configuração da curiosidade humana em torno de certos achados. A etnociência ajuda a desvendar as "verdades" que o saber popular camufla, para compreendê-las em seus próprios termos e interpretar o seu significado dentro daquele universo cultural. Somente após isso será possível estabelecer pontes com o rigor acadêmico e sugerir possibilidades de investigação convergentes com os conhecimentos científicos. Ignorar este exercício, ou subestimar outras formas de conhecimento dentro de certas experiências socioculturais, para Freire, é um erro científico, um equívoco que revela certa ideologia elitista e torna míopes qualquer forma de ensino/aprendizagem (FREIRE, 2006a, p. 85).

Obviamente que Freire se inscreve numa compreensão mais ampla de Ciência, crítica ao etnocentrismo academicista que adota o rigor empírico como único referencial para a validação do conhecimento. Com base nas intuições do físico Márcio D’Olne Campos, que criou o vocábulo "suleamento" para se contrapor aos aspectos ideológicos impregnados na linguagem utilizada pelo georreferenciamento dos pontos cardeais sem considerar a localização de quem está posicionado ao sul (D'OLNE CAMPOS, 1991), Freire adota o verbo "sulear" como mote político-pedagógico para afirmar as visões epistêmicas e alternativas dos países periféricos, em contraposição ao "norteamento" imperialista e eurocêntrico.

"Sulear" a produção do conhecimento consiste em assumir uma posição de resistência anticolonial, em que, por um lado, busca-se preservar o que há de valioso nos conhecimentos subalternos presentes nas inúmeras tradições culturais periféricas. $E$, por outro lado, se exercita a vigilância epistêmica de não aceitar passivamente o modo dominante de denominar a "posse do conhecimento", como se detivesse os cânones do único caminho metodológico possível para se chegar à "verdade".

O ensino de Ciências não se confunde, portanto, com a transmissão de enunciados, fórmulas, leis e teorias complexas que configuram quase que um ensino de história dos conhecimentos científicos. Muito menos com a apresentação superficial das descobertas científicas que se consagraram e são amplamente aceitas pela comunidade científica. Mas pressupõe que se ensine a "pensar cientificamente", pensar certo, a processar criticamente a prática da pesquisa, da investigação, da procura pela superação da ingenuidade que se Ideação. Revista do Centro de Educação, Letras e Saúde. v. 23, n², 2021. e-ISSN: 1982-3010. 
alonga no exercício do rigor necessário para defender e justificar as descobertas. Rigor que não se sobrepõe ao senso comum, pois exige uma atitude radical de respeito e compreensão dialógica, bem como de tolerância diante das diversas formas de "pensar diferente".

No que se refere ao exercício crítico de contextualização conjuntural e histórica sobre os conteúdos abordados na área de ciências, em perspectiva crítica com relação às dimensões econômicas, culturais, sociais, políticas e éticas, Freire afirma: "Ao sublinhar a importância fundamental da ciência, a educadora progressista deve enfatizar também aos meninos e às meninas pobres como aos ricos o dever que temos de permanentemente nos indagar em torno de a favor de que e de quem fazemos ciência" (FREIRE, 2000, p. 44). Ou seja, o ensino de Ciências não pode ser abstraído das relações de poder em que se encontra a produção do conhecimento científico. Por isso, independente da área de conhecimento, sempre é possível explorar alternativas críticas para tecer uma compreensão da realidade concreta. Eis o exemplo que Freire utiliza:

Uma vez que se opta pela transformação, pode-se levar para o seminário pedaços da realidade [...]. Se um professor de Matemática ou de Física não consegue descobrir item algum do relatório do Banco Mundial relacionado com sua disciplina, então não acredito em sua capacidade, porque há sempre formas de se fazer isso. Suponhamos que você leve um relatório do Banco Mundial a uma sala de aula de Biologia. Se o banco exige austeridade nos empréstimos ao Terceiro Mundo - preços mais altos, salários mais baixos e cortes no programa social -, os alunos de Biologia podem calcular os efeitos dessa medida sobre a dieta familiar, quantas calorias a menos essas pessoas vão comer? Que alimentos mais baratos procurarão? Essa dieta aumentará a taxa de doenças e mortalidade infantil? Todas essas coisas têm a ver com a "iluminação" da realidade: fazer com que os estudantes compreendam que conhecer não é só comer conhecimento, e que comer também é uma questão de política! (FREIRE, 1986, p. 35).

A riqueza dos exemplos que Freire oferece demonstra a versatilidade e a grande maleabilidade que o pensamento político-pedagógico pode inspirar aos educadores no ensino de Ciências. Um pensamento que problematiza e articula dialeticamente o conhecimento científico para além de sua pretensa neutralidade. Assim, poderá estabelecer relações entre o que é específico do componente curricular em cada disciplina, com as questões ideológicas, históricas, políticas, sociológicas, econômicas e éticas, como se fossem pontes de acesso ao desconhecido. Este é espírito que deve animar o exercício crítico deste componente curricular em vista da aproximação com a totalidade da realidade, do aprimoramento da prática educativa e, consequentemente, no desenvolvimento da própria 
autonomia de educandos e educadores, num contínuo, recíproco e simbiótico processo de superação.

O ensino de Ciências na ótica freiriana pode contribuir decisivamente para uma abordagem densa sobre uma infinidade de problemas globais que ameaçam a vida local: como o aumento crescente da poluição ambiental ocasionado, em grande parte, pela aceleração desenfreada das economias consumistas do primeiro mundo; a consideração dos cientistas sobre a elevação da temperatura global neste século, o que implica no derretimento das calotas polares que acarretaria o aumento de água dos oceanos e o alagamento das populações costeiras; o impacto climático sobre a produção de alimentos; o processo de desertificação de regiões produtivas; a possibilidade de escassez de água potável; a exploração predatória dos recursos energéticos naturais finitos (metais, madeiras nativas, petróleo). Tudo isso numa perspectiva dialética, partindo do local, passando ao regional e chegando ao global (totalizante) para, novamente, retornar ao ponto de partida local.

Poderíamos contemporizar estas hipóteses com o problema mundial da pandemia de Covid19, por exemplo. Um fato que não pode encerrar sua discussão meramente do ponto de vista biológico, estatístico ou matemático, como se o cálculo da expansão de casos contaminados e óbitos proporcionais esgotassem a discussão sobre o assunto. Pelo contrário, há que se problematizar à luz da política, como o Estado implementa políticas públicas de contingenciamento sanitário; da economia, com os prováveis impactos do isolamento social na renda familiar e na dinâmica das relações socioeconômicas, como se evidenciam e escancaram as desigualdade sociais neste cenário; da ética, sobre como alguns indivíduos relativizam as recomendações da Organização Mundial da Saúde (OMS) e proliferam o contágio, ou que relativizam a eficácia das vacinas e condenam o uso máscaras; da educação e da tecnologia, sobre como este cenário altera substancialmente as relações na comunidade educativa e exige novas atitudes de interação virtual, tanto dos educadores, quanto dos educandos; da produção científica, sobre como a indústria farmacêutica recebe quantias vultuosas de financiamento público ou privado, e em que sentido isso é revertido à sociedade, etc.

Por fim, para concluir, reconhecemos que Paulo Freire oportuniza, em seu pensamento político-pedagógico, aspectos relevantes a serem considerados no debate sobre o ensino de Ciências. Sua principal preocupação consiste em demonstrar que não há 
verdades absolutas nos saberes humanos sobre a natureza e, a partir deste primeiro pressuposto, conclui-se que não há também caminhos absolutos. Os pressupostos epistemológicos freirianos questionam qualquer forma de etnocentrismo acadêmico, pois não admitem sobreposição de saberes e hierarquização de conhecimentos. Isso, porém, não significa que rejeite o rigor científico em detrimento do senso comum, mas sugere o exercício da humildade e de respeito frente as múltiplas maneiras de saber configuradas em diversas culturas ou realidades sociais para explicar o mundo.

Contudo, o mero respeito não passa de uma observação passiva da realidade alheia. Freire nos provoca a irmos ao encontro do outro, para compreendê-lo em seus próprios termos. Isso exige que também nos tornemos pesquisadores, para aprofundar a compreensão crítica da nossa própria prática educativa, a fim de que esta se transforme numa atividade investigativa, de aprendizado contínuo e recíproco, em que haja a troca de sentidos e a comunhão da curiosidade ingênua com a curiosidade epistemológica. Com este espírito é possível construir pontes de acesso para evitar o distanciamento entre o conhecimento científico e o saber popular, entre as Ciências e o "saber de experiência feito" dos indivíduos, entre o "conceito" e a realidade.

Acreditamos que, com esta discussão, apresentamos alguns dos elementos centrais que possam subsidiar o debate sobre o ensino de Ciências a partir da ótica freiriana. Aproximar a academia dos achados populares, mas também permitir a aproximação do saber popular à academia é uma responsabilidade contínua para educadores e educadoras que se preocupam com o caráter problematizador da educação libertadora.

\section{REFERÊNCIAS}

BEISIEGEL, C. R. Paulo Freire. Recife: Fundação Joaquim Nabuco, Editora Massangana, 2010.

D'OLNE CAMPOS, M. "A Arte de Sulear-se: Atividades". In: Interação Museu-Comunidade pela Educação Ambiental, Manual de apoio a Curso de Extensão Universitária, Teresa Cristina Scheiner (coord.), pp. 79-84, TACNET Cultural UNIRIO, Rio de Janeiro, 1991. Disponível em: http://sulear.com.br/beta3/wp-content/uploads/2017/03/CAMPOS-M-D-AArte-de-Sulear-2-Ativs-1991.pdf Acesso em 21 de dez. de 2020.

FISCHER, N. B.; LOUSADA, V. L. Saber (erudito/saber popular/saber de experiência). In: STRECK, D. R; REDIN, E.; ZITKOSKI, J. (Orgs.). Dicionário Paulo Freire. Belo Horizonte: Autêntica Editora, 2008.

FREIRE, P. Educação como prática da liberdade. São Paulo: Paz e Terra, 1967. 
FREIRE, P. Pedagogia do oprimido. 18. ed. Rio de Janeiro: Paz e Terra, 1988.

FREIRE, Paulo. Introdução: o trabalho em educação considerado em três dimensões (entrevista). In: NOGUEIRA, A. (Org). Contribuições da interdisciplinaridade para a ciência, para a educação, para o trabalho sindical. Nova Petrópolis: Vozes; Curitiba: APP Sindicato, 1994.

FREIRE, P. Professora sim, tia não: cartas a quem ousa ensinar. São Paulo: Olho d'Água, 1997.

FREIRE, P. Pedagogia da indignação: cartas pedagógicas e outros escritos. São Paulo: UNESP, 2000.

FREIRE, P. Pedagogia dos sonhos possíveis. (Org. e apres.) Ana Maria Freire. São Paulo: UNESP, 2001.

FREIRE, P. Pedagogia da tolerância. Ana Maria Araújo Freire (Org. e Notas). São Paulo, UNESP, 2004.

FREIRE, P. A Educação na cidade. Prefácio de Moacir Gadotti e Carlos Alerto Torres. 6. ed. São Paulo: Cortez, 2005.

FREIRE, P. Pedagogia da esperança: um reencontro com a Pedagogia do oprimido. São Paulo: Paz e Terra, 2006a.

FREIRE, P. Pedagogia da autonomia: saberes necessários à prática educativa. 34 . ed. São Paulo: Paz e Terra, 2006b.

FREIRE, P.; FAUNDEZ, A. Por uma pedagogia da pergunta. Rio de Janeiro: Paz e Terra, 1985.

FREIRE, P.; SHOR, I. Medo e ousadia: o cotidiano do professor. Trad. Adriana Lopez; Rio de Janeiro: Paz e Terra, 1986.

FREIRE, P. Leitura da palavra... leitura do mundo. O Correio da UNESCO, São Paulo, v. 19, n. 2, p. 4-9, fev. 1991. Entrevista concedida a Marcio D'Olne Campos. Disponível em: http://acervo.paulofreire.org:8080/xmlui/handle/7891/2473. Acesso em 20 de dez. de 2020.

FREIRE, P. Pedagogia do compromisso: América Latina e Educação Popular. (Org.) Ana Maria Araújo Freire. 1a ed. Rio de Janeiro/São Paulo: Paz e Terra, 2018.

MARX, K. Contribuição à crítica da economia política. Trad. Maria Helena Barreiro Alves. São Paulo: Martins Fontes, 1977.

RICOEUR, P. Interpretação e ideologias. 4. ed. Rio de Janeiro: Francisco Alves, 1988.

ZAUITH, G.; HAYASHI, M. C. P. I. A influência de Paulo Freire no ensino de ciências e na educação CTS: uma análise bibliométrica. Revista HISTEDBR On-line, Campinas, SP, v. 13, n. 
49, p. 267-293, jul. 2013. ISSN 1676-2584. Disponível em: https://periodicos.sbu.unicamp.br/ojs/index.php/histedbr/article/view/8640332/7891. Acesso em: 10 ago. 2018. doi: https://doi.org/10.20396/rho.v13i49.8640332.

Recebido em 13 de agosto de 2020. 